\title{
ANTHROPOMORPHISM IN ADVERTISING: THE EFFECT OF ANTHROPOMORPHIC PRODUCT DEMONSTRATION ON CONSUMER PURCHASE INTENTION
}

\author{
Dwinita Laksmidewi ${ }^{1 *}$, Harry Susianto ${ }^{2}$, and Adi Zakaria Affff ${ }^{3}$ \\ ${ }^{1}$ Faculty of Economics and Business, Universitas Katolik Indonesia Atma Jaya, \\ Jl. Jenderal Sudirman No. 51, Jakarta 12930, Indonesia \\ ${ }^{2}$ Faculty of Psychology, Universitas Indonesia, Depok, Indonesia \\ ${ }^{3}$ Faculty of Economics and Business, Universitas Indonesia, Depok, Indonesia \\ *Corresponding author: dwinita.laksmi@atmajaya.ac.id
}

Published online: 30 June 2017

To cite this article: Laksmidewi, D., Susianto, H., and Afiff, A.Z. (2017). Anthropomorphism in advertising: The effect of anthropomorphic product demonstration on consumer purchase intention. Asian Academy of Management Journal, 22(1), 1-25. https://doi.org/10.21315/aamj2017.22.1.1

To link to this article: https://doi.org/10.21315/aamj2017.22.1.1

\begin{abstract}
Anthropomorphism refers to the tendency to imbue the nonhuman objects with human-like characteristics, intentions, and behaviour. This study aims to examine that demonstrating the efficacy of the product using human behaviour (anthropomorphic demonstration) in advertising is more effective in explaining the efficacy of the products that are difficult to understand. We used hero archetype to illustrate the product efficacy in human behaviour. The results of two studies suggest that anthropomorphic demonstration has a positive effect on perceived product efficacy. These studies also find that anthropomorphic demonstration effect would be higher when the product represented character has high similarity to humans. Consumers successfully anthropomorphise the product when the products are presented as human which have human-like behaviour and human-like physical appearance. Further, the results indicate that perceived product efficacy significantly mediates the effect of anthropomorphic demonstration on purchase intention.
\end{abstract}

Keywords: product demonstration, anthropomorphism, advertising, perceived product efficacy, purchase intention

(C) Asian Academy of Management and Penerbit Universiti Sains Malaysia, 2017. This work is licensed under the terms of the Creative Commons Attribution (CC BY) (http://creativecommons. org/licenses/by/4.0/). 


\section{INTRODUCTION}

Anthropomorphism is defined as "the tendency to imbue the real or imagined behavior of nonhuman agents with humanlike characteristics, motivations, intentions, or emotions" (Epley, Waytz, \& Cacioppo, 2007, p. 864). People have a tendency to anthropomorphise objects (Guthrie, 1995), such as seeing faces in the clouds, threatening an angry volcano, personify pets, or talking to a computer. Every day, public is bombarded by advertisements with human-like images mosquitoes compete in boxing, batteries shoot at targets and dance like human, pans and cups are able to speak, fruit with eyes, arms, and legs, and many spokes character created by the advertiser. Human-like form, behaviour, and character are lasting and powerful because they are embedded in the mind of every human as anthropomorphism. How can the benefits of anthropomorphism be realised in advertising? The unique form of human-like characters is preferred by consumers and creates a product liking, but advertising is often not merely satisfied with the product liking. Advertising wants to convince consumers that the product is effective to overcome the consumers' problems.

A recent TV ad in Indonesia for 'Baygon', an insect repellent, shows a boxing match between mosquitoes against Baygon. In the boxing ring, the Baygon smoke transformed into a human hand, punched the mosquitoes, and the frightened mosquitoes bounced into the air and disappeared. The boxing match, which exists in the real human world, ended with the human hand winning and is used to illustrate the efficacy of the product. The ad shows how the powerful insect repellent defeated the mosquitoes, in a way that is more familiar, in human terms.

This study is focused primarily on this form of anthropomorphising that is presenting the product efficacy in human terms. The power of familiarity in anthropomorphism (Guthrie, 1995) should be utilised in many advertising purposes, persuading product personality (Aaker, 1997; Aggarwal \& McGill, 2012; Folse, Netemeyer, \& Burton, 2012), product liking (Aggarwal \& McGill 2007; Landwehr, McGill, \& Herrmann, 2011), product risk (Kim \& McGill, 2011), and product efficacy. The research question is to explain the efficacy of a product using human behaviour; it can be easier for consumers to understand and convince the perceived product efficacy. Therefore, we conducted two studies to support our argument that explaining the efficacy of the product in advertising would be more effective if it is being delivered using anthropomorphic demonstration. Study 1 compared anthropomorphic demonstration with speaking behaviour. While in Study 2, we focused on the physical appearance of anthropomorphic character in the demonstration. 
Previous researches in the field of marketing have been interested in how anthropomorphism affects consumers' evaluation and liking of a product. The anthropomorphic appearance of a product, such as an apparent smile in the grill of a car or hand phone, led to increase the liking of that product (Aggarwal \& McGill, 2007; Landwehr et al., 2011), reduce the desire to replace the product (Chandler \& Schwarz, 2010), and affect consumers' risk perception (Kim \& McGill, 2011). A variety of product design with a diverse specific emotion (Smith, 2008) and a various design of front fascia with the manipulation of baby schema (Miesler, 2011) have a positive effect on product evaluation. These researchers found that presenting products with human-like physical features led to consumers' positive response. However, these previous studies have not been linking anthropomorphism with the perception of the product efficacy. Consumer perceptions of the product efficacy become important when the product is proposed for the efficacy benefits, not because of the appearance design.

On the other side, some previous marketing researches did not only consider the physical resemblance to human that could trigger anthropomophism, but also from the side of human behaviour or human mental states (Epley et al., 2007). Delbaere, McQuarrie, and Philips (2011) showed that picture in a print ad that represented a product engaged in human behaviour can trigger anthropomorphism and led to increase in brand liking. Brands that are illustrated to behave like human can influence consumers to behave as they reflect the brand image (Aggarwal \& McGill, 2012). May and Monga (2014) proposed time anthropomorphism, which described that people have a tendency to imbue time with human-like mental states, reduce consumer patience, and then influence the purchase decision.

Although it is not explicitly associated with anthropomorphism, spokes character has been widely discussed on previous research. Spokes character inanimate objects are attributed to the physical characteristics and human trait to be alive and be a liaison relationship between the brand and the consumer. Research on spokes character showed a positive effect on consumer behaviour (Folse et al., 2012; Pierce, 2002; Lin \& Wang, 2012). Previous study focused on the appearance of spokes character that consumers preferred, the nature of which was reflected, and its effect on product evaluation (Stafford, Stafford, \& Day, 2002; Garretson \& Burton, 2005; Garretson \& Niedrich, 2004). The behaviour performed by spokes character in the ad has not been discussed.

As a tendency in every human being, anthropomorphism is utilised in the field of marketing because it is believed to be a positive influence on consumer behaviour (Guthrie, 1995). Although not explicitly mentioned the term anthropomorphism, advertising literatures have discussed the criteria and roles, as well as the positive 
effects of spokes character on consumer. Approximately, the last decade's marketing literatures separately discussed anthropomorphism from the characteristics side of the product's physical appearance like a human, and from the side of how the product behaves like a human. However, there is no literature that examines both characteristics simultaneously, as well as how anthropomorphic product has effect on product efficacy. This study examines a product performing similar to human and behaves like a human being and how it affects perceived product efficacy. In this study, advertising character is the embodiment of the product, taking an active role to demonstrate the efficacy of the product (Callcott \& Lee, 1994) using the behaviour that is usually done by human. We assess that a combination of humanlike physical appearance, character, and human-like behaviour are characteristics of complete human that are expected to induce more anthropomorphism; a research gap is examined in this study.

Our findings offer an important contribution in how the anthropomorphism is utilised to benefit in advertising, especially to convince about product efficacy. When the efficacy of the product cannot be seen or touched, it is difficult to explain to the consumers. We argue that messaging product benefits in human terms enables customers to understand when the efficacy of the product is abstract and is difficult to comprehend. Our framework explanation refers to the familiarity account of anthropomorphism proposed by Guthrie (1995, p. 65), "In order to explain the nonhuman world, we rely on our understandings or ourselves because these are easiest or most reliable".

A second contribution of this research is to combine elements of anthropomorphism in product demonstration tactics in advertising, which are commonly known as a demonstration of the product in actual use (Belch \& Belch, 2012). In our research, efficacy of the products demonstrated in human-like behaviour. We used hero archetype (Mark \& Pearson, 2001) which showed the efficacy of the product using the fight scene of hitting, kicking, with the sword slash, causing the death of the enemy. Ad character in this study plays an active role, demonstrating the efficacy of the product (Callcott \& Lee, 1994). Besides human-like appearance of ad character, we also believe that its human-like behaviour may trigger higher anthropomorphism, which increase the perceived product efficacy further.

We also consider the elements of motion, which has not been considered in previous studies. As proposed by Epley et al. (2007), there are two dimensions of similarity with humans that are important for anthropomorphism to occur, namely similarity in motion and similarity in morphology. Our research is conducted using TV advertising as stimuli, in order to demonstrate an object motion. The product presented on the TV ad not only has a human-like appearance, but also behaves 
like humans. In Study 1, we show that this demonstration of product efficacy using a human-like behaviour has positive effects on perceived product efficacy.

Prior research showed that mental state was a necessary condition to humans, and the presence of human physical appearance and motion makes the mental state of the object more perceivable (Connel, 2013; Morewedge, Preston, \& Wegner, 2007). Therefore, we argue that the presence of physical similarity is important, and when people feel the presence of human mind, intention, and emotion of advertising character, people will believe its efficacy. We test the effect of the degree of physical similarity in anthropomorphic demonstration on perceived product efficacy in Study 2.

\section{THEORETICAL BACKGROUND AND HYPOTHESES}

\section{Anthropomorphism in Advertising}

Consumer behaviour researchers have been focusing their research works on how anthropomorphism affects consumers' evaluation and liking of a product. The anthropomorphic appearance of a product, such as an apparent smile in the grill of a car, leads to increased liking of that product (Aggarwal \& McGill, 2007; Landwehr et al., 2011), reduces the desire to replace the product (Chandler \& Schwarz, 2010), and affects consumers' risk perception (Kim \& McGill, 2011). These researchers found that presenting products with human-like physical features led to consumers' positive response. Prior research also showed that pictures in a print ad that represent a product as engaged in human behaviour can trigger anthropomorphism and led to increased brand liking (Delbaere et al., 2011). These previous researches performed using print media as a stimulus, in which there was no human-like motion of objects. Heider and Simmel (1944) and Morewedge et al. (2007) showed that motion could trigger anthropomorphism; hence we examined the anthropomorphism presentation by using TV as the advertisement media.

Advertisers attempted to trigger consumers' anthropomorphism by various approaches. One approach widely used is creating a character which is shaped like a human, called anthropomorphic character. In our research, we created a hero character as a symbol of a product; that had the nature and behaviour of the product. The nature of the product which is brave, strong, and tough, is personified by the hero. Previous studies showed that ad characters have a positive effect on consumer attitudes toward the brand, brand trust, and the willingness to pay a premium price (Folse et al., 2012). Ad characters also create brand identity, positive feeling, memorable brand, excitement and uniqueness; thus, they affect the purchase 
intention to the product (Pierce, 2002; Lin \& Wang, 2012). Characters have active roles in promoting a product, including demonstrating or speaking for the product (Callcott \& Lee, 1995). This research combines the positive effects of advertising character and the motion in order to trigger audience anthropomorphism. The active roles of the ad characters demonstrate the efficacy of the product using human behaviour and to be called anthropomorphic demonstration.

\section{Anthropomorphic Demonstration}

Demonstration tactics have long been recognised in advertising, designed to illustrate the key advantages of the product in actual use, or in some gradual conditions (Belch \& Belch, 2012). Demonstration tactics in an ad help consumers to make purchase decisions firmly because consumers see the efficacy of the product in the ad (O'Guinn et al., 2009). Deighton, Romer, and McQueen (1989) categorise ad as demonstration with the plot and narrative, but without character. Following the previous, this research used "demonstration" term as advertisements with the plot and narrative, but with the presence of the anthropomorphic characters.

Brand, which was created to behave like humans affect consumers to behave according to the image of brand behaviour (Aggarwal \& McGill, 2012). This indicates that products behaviour have a positive effect on consumer behaviour. Anthropomorphism can be generated through the object illustrated having human character and behaviour, such as time anthropomorphism (May \& Monga, 2014) which illustrates that the time has properties like a human and affect consumer purchasing decisions. In this study, we illustrate the benefits of products like the human behaviour, so that the efficacy of the product can be seen through demonstrating the benefits of the product.

We argue that the demonstration using human behaviour (anthropomorphic demonstration) provides the ease of understanding the advertising message. We expect that the anthropomorphic demonstration could trigger anthropomorphism. According to Guthrie (1995), anthropomorphism gives a familiar sense that makes it easier for people to understand. The ease becomes a positive experience, more attractive, and fun for consumers, thereby increasing consumer preference for products (Labroo, Dhar, \& Schwarz, 2008), inducing a feeling to know, and has a positive impact on mind and behaviour (Kim \& Labroo, 2011).

Delivery of the product benefits messages that are familiar makes it clearer to the consumers. Study by Zhu, Billeter, and Inman (2012) shows that the image differences in an ad that informs about product efficacy affect the consumer's perceived product efficacy; the clearer the image ad provides information of a 
product efficacy, the higher the perceived product efficacy. Perception of the efficacy of the product as a measure of the effectiveness of the product has been used in research in the field of marketing (Shiv, Carmon, \& Ariely, 2005; Cox, Cox, \& Mantel, 2010). Thus if the benefits of the product are difficult to explain, the delivery of the product benefits message can be more familiar and easier to understand when it is presented with the help of an anthropomorphic behaviour.

H1: Perceived product efficacy will be higher, if the product efficacy in the ad messages is conveyed in anthropomorphic demonstrations compared to anthropomorphic speaking.

The effectiveness of an ad can be measured by how it affects the consumer purchase intention (Lutz, MacKenzie, \& Belch, 1983). Previous research has shown that the way the message conveyed in ad affects consumer evaluation of the product (McQuarrie \& Phillips, 2005; Peracchio \& Meyers-Levy, 1994), consumer attitude toward the brand (Labroo et al., 2008; Arias-Bolzmann, Chakraborty, \& Mowen, 2000), and consumer purchase intention (Putrevu \& Lord, 1994). Consumer perceived product efficacy affects the consumption behaviour (Shiv et al., 2005), and the purchase intention (Cox et al., 2010). Thus, we expect consumer perceptions of the efficacy of the product in the ad will affect the purchase intention.

H2: Anthropomorphic behaviour affects the purchase intention through the mediation of the perceived product efficacy.

\section{Perceived Similarity}

Anthropomorphism involves attributing a human-like physical appearance (e.g., a face, hands), and human-like mental state (e.g., intentions, conscious awareness) to nonhumans (Waytz, Cacioppo, \& Epley, 2010). Human mind or mental state is considered as the defining feature that distinguishes humans from other objects (Waytz et al., 2010). People are likely to infer ability from physical cues, and tend to anthropomorphise things that look and move like humans (Morewedge et al., 2007; Connell, 2013). If an object has the appearance and moves like a human, then the object is perceived to have mental conditions like humans (Waytz et al., 2010).

Humans have a tendency to anthropomorphise objects based on motion and shape of the physical object. In a study by Heider and Simmel (1944) in which participants anthropomorphise triangular geometric stimulus, lines and dots which moved, participants imagined and felt stories and human emotions, although there did not seem to be any human physical form. Animals, robots, and animations 
which moved with human-like velocity were perceived like humans (Morewedge et al., 2007). Moreover, Connell (2013) found out that an animal mascot which has physical similarities with humans (bear vs. lion) were perceived like human, and when the animal mascot was depicted anthropomorphically (playing basketball vs. not doing anything) cause a positive evaluation of a personal relationship with brand and positive affect.

Research in marketing shows similar results. For instance, Aggarwal and McGill (2007) found out the picture of the product with the human schema (portrayed products as if a family) led to a more positive evaluation of the product. Their study also showed that the product (portrayed products as if twins) with good human nature (the good twin vs. evil twin) led to a more positive evaluation of the product. Human physical similarities to a car (lights as eyes and grille as mouth) affected product evaluation (Aggarwal \& McGill, 2007) and made the consumer not want to change their products (Chandler \& Schwarz, 2010), affected perception of friendliness and aggressiveness, and finally affected sales (Landwehr et al., 2011). These studies show that physical appearance similar to humans, trigger anthropomorphism, which had positive effects on product evaluation.

H3: The demonstration performed by anthropomorphic character perceived human-like will result in a higher perceived product efficacy compared to anthropomorphic character perceived less human-like.

Although all people have a tendency to anthropomorphise objects, it does not mean that such anthropomorphism has a tendency to be shared in equal degrees by everyone (Waytz et al., 2010). Stable individual differences in the tendency to anthropomorphise could arise from differences in culture, norms, experience, education, and attachment to human and nonhuman agents (Epley et al., 2007). For instance, individuals who feel lonely (sociality motivation) will have a high tendency of anthropomorphism (Epley et al., 2008), low-power individuals will also have a high tendency of anthropomorphism (Kim \& McGill, 2011; May \& Monga, 2014). We examine the possibility that people with low anthropomorphic tendency will have a positive response when a character has high similarity to human. To achieve this, we test the moderating role of the anthropomorphic tendency.

H4: The effect of anthropomorphic demonstration performed by the ad character which is very similar, moderately similar, or less similar to humans, on the perceived product efficacy, is moderated by anthropomorphic tendencies. 


\section{STUDY 1}

We designed Study 1 to test the idea that anthropomorphic demonstrations have more positive effect on the product efficacy than speaking (H1), and to test the mediating role of perceived product efficacy (H2). Demonstration was conducted by a human-like character, a symbol of the product, who behaves like humans to demonstrate the efficacy of the product.

\section{Method}

\section{Design and participants}

The experiment had three treatment conditions (anthropomorphic behaviour: demonstration vs. speaking, and non-anthropomorphic) between participants design. One hundred and fifty undergraduate students ( 79 male and 71 female) from Universitas Katolik Indonesia Atma Jaya (UAJ) Jakarta, Indonesia, participated in an exchange for partial fulfilment of a course requirement. Participants were randomly assigned to one of the three conditions.

\section{Stimulus development}

In order to create the experimental stimuli, we conducted five pilot studies. Each of our pilot studies was conducted among 40 different undergraduate students at UAJ, Jakarta. The first pilot study aimed to select the advertised product. We established criteria for selecting the product advertised, such as the product could be have not visible reactions (abstract); this study selected healthcare products. Participants were told to choose the product(s) that they had purchased and used; the most frequently selected product was the influenza medicine. The second pilot study had the purpose of obtaining brand personality. A list of descriptions of 12 archetypes (Mark \& Pearson, 2001), with alphabetical coded archetype names, were created. The participants were asked to imagine a powerful flu medicine and select an archetype which fitted with it. The brand personality chosen was the hero archetype. Subsequently, we conducted the third pilot study aiming to create the hero character and its enemy. The participants were asked to write a description of hero visualisation, including the body shape, the face, the outfit, the country of origin, and the weapon used. They were asked to write a description of the hero's enemy, how the hero fights with the enemy, and how the enemy is defeated. Based on the third pilot study result, we asked an artist to create five hero characters and five monster characters. These hero and monster characters were selected during our fourth pilot study. To control the effects of prior attitudes toward a brand, a fictitious brand name was used for the product and this leads to our fifth pilot study. 
The fifth pilot study aims to select a fictitious brand name. Our 40 participants selected a brand name from a list of fictitious flu medicine brand names and "Antifluenza" is the most frequently selected.

Based on the result of the pilot studies, three different versions of a TV ad were created (Appendix 1). In the anthropomorphic condition (demonstration and speak), the product was symbolised by a human-like red hero character and the flu symptoms was symbolised by a character of horrific green human-like monsters. (1) In demonstration condition, we designed a storyline to represent the product efficacy. The storyline begin with an overview of the flu symptoms, which are sneezing, nasal congestion, fever, and headache. When these symptoms were attacking, Antifluenza emerged from the packaging and there was a fierce battle between Antifluenza against flu symptoms. The fight ended with the killing of the flu symptoms by Antifluenza sword attack. The flu symptoms death, smashed into pieces, disappeared, and Antifluenza withdrawn to the packaging. (2) In the speaking condition, the hero character was speaking about the product efficacy and the flu symptoms were displayed in the verbal form. (3) In non-anthropomorphic condition, there was no hero character and the flu symptoms were displayed in the verbal form. All three TV ads had the same narration, full animation, 2D characters, and 30 seconds of duration.

\section{Procedure}

Participants participated in the experiment in groups of six to eight. Participants were told that the purpose of the study was to obtain their evaluation of a new product advertisement that was being tested by a corporation and signed informed consent. Participants had advertising exposure - a TV ad was shown to the participants on the screen twice. After watching the ad, participants completed dependent measures and indicated their attitude toward ad $(\alpha=0.841)$ - how strongly they agree that the TV ad was interesting, informative, easy to understand, and good. To assess participants' mood after the ad exposure, participants rated about to what extent they felt about from being sad to happy, bad mood to good mood, irritate to please, and depress to cheerful (6-point scales) $(\alpha=0.907)$. Finally, participants responded to the anthropomorphism scale, attention to the ad and standard demographic questions. Attention to the ad $(\alpha=0.621)$ was measured by two statements: "I paid a lot of attention to the ad" and "My mind was somewhere else" (6-point Likert scales; 1 = strongly disagree, 6 = strongly agree). 


\section{Dependent measures}

Participants were asked to answer three questions measuring perceived product efficacy $(\alpha=0.737)$ adapted from Cox et al. (2010): "Antifluenza effective to overcome the flu symptoms", "Antifluenza works to eliminate the flu symptoms", and "Antifluenza relieves the flu". Next, the participants answered two questions measuring purchase intention $(\alpha=0.809)$ adapted from Fishbein and Ajzen (1975): "If I need a flu medicine, I intend to buy Antifluenza" and "If I need a flu medicine and just Antifluenza is available, I intend to buy Antifluenza". All items were answered on a 6 -point Likert scales $(1=$ strongly disagree; $6=$ strongly agree). All instruments of measurement in this study are valid, with factor loading $>0.7$.

\section{Results}

\section{Manipulation checks}

To assess whether the anthropomorphic demonstration had triggered higher anthropomorphism, the participants indicated whether the ad character had human traits. Anthropomorphism was measured by four statements $(\alpha=0.805)$ : "In the ad, Antifluenza is like a person", "Antifluenza comes alive", "Antifluenza looks brave", and "Antifluenza is fighting to defeat flu symptoms". ANOVA result showed there were significant differences among demonstration condition, speak condition, and non-anthropomorphic condition $[F(2.147)=55.520, p=0.000]$. The contrast test showed that the participants significantly anthropomorphise ad character more in the demonstration condition than in the non-anthropomorphic condition $\left[M_{\text {demonstration }}=4.590, S D=0.762 ; M_{\text {non-antrop }}=2.740, S D=0.933\right.$; $t=10.485, p($ one-tailed $)=0.000]$ and in the speak condition $\left[M_{\text {demonstration }}=4.590\right.$, $S D=0.762 ; M_{\text {speak }}=3.505, S D=0.941 ; t=6.150, \quad p($ one-tailed $\left.)=0.000\right]$, suggesting the manipulation was successful. To strengthen the control of the effect of the other factors, we measured the attention to the ad $[F(2.147)=0.545$, $p=0.581]$, subjective knowledge about health $[F(2.147)=0.912, p=0.404]$, and health motivation of participants $[F(2.147)=0.372, p=0.690]$. Results showed that there were no significant difference at all three conditions, as expected.

\section{Perceived product efficacy}

A one-way ANOVA was performed using the average of the three questions on perceived product efficacy as the dependent variable. As predicted, the main effect of anthropomorphic behaviour was significant $[F(2.147)=23.598, p=0.000]$. Dunnet-test $(>$ control) showing that participants in the demonstration condition $\left(M_{\text {demonstration }}=4.560, S D=0.541 ; M_{\text {non-antrop }}=3.520, S D=0.999, p=0.000\right)$ and in 
the speak condition $\left(M_{\text {speak }}=3.893, S D=0.688 ; M_{\text {non-antrop }}=3.520, S D=0.999\right.$, $p=0.015$ ) expressed a higher perceived product efficacy than in the nonanthropomorphic condition. The contrast test showed that the demonstration condition expressed a higher perceived product efficacy than in the speaking condition $(t=5.387, p=0.000)$. These results support H1.

\section{Mediation analysis}

We performed the mediation analysis with purchase intention as the dependent variable, anthropomorphic behaviour as the predictor, and the perceived product efficacy as the mediating variable, using the OLS regression PROCESS SPSS macro model 4 and bootstrap analysis (Hayes, 2013; Hayes \& Preacher, 2013). We had a three-categorical independent variable; two dummy variables were constructed, with non-anthropomorphic condition as the reference category. The effect of anthropomorphic behaviour on perceived product efficacy $\left(a_{1}=0.3733\right.$, $t=2.4341, p<0.050$ and $\left.a_{2}=1.0400, t=6.7806, p<0.010\right)$ and the effect of perceived product efficacy on purchase intention $(b=0.7145, t=8.2139, p<0.010)$ were both significant (Table 1). The initial direct effect of anthropomorphic behaviour on purchase intention $\left(c^{\prime}{ }_{1}=0.7200, p<0.010\right.$ and $c_{2}^{\prime}=1.2000$, $p<0.050)$ were reduced but significant $\left(c_{1}=0.4532, p<0.010\right.$ and $c_{2}=0.4569$, $p<0.050$ ), indicating that partial mediation occurred (Baron \& Kenny, 1986). More importantly, the indirect effect of anthropomorphic behaviour on purchase intention through perceived product efficacy was significant $\left[a_{1} b=0.2668,95 \% C I\right.$ $(0.0161 ; 0.5353)$ and $\left.a_{2} b=0.7431,95 \% C I(0.4484 ; 1.0667)\right]$. These result showed that the effect of anthropomorphic behaviour on purchase intention was mediated by perceived product efficacy. Thus, $\mathrm{H} 2$ was supported. Advertising messages using anthropomorphic demonstration generated perceived product efficacy more positively than verbal behaviour or non-anthropomorphic, and then had a positive effect on purchase intention.

\section{Discussion}

The main important theoretical implication of this study is that sometimes, the efficacy of the product is difficult to comprehend because it is abstract and cannot be seen or touched. In this case, demonstrating the efficacy into human-like behaviour will be easier to comprehend because human characteristics are familiar to consumers. The product efficacy that was visualised into human behaviour (fight) generated the greater anthropomorphism, and it was to be the most effective way to deliver the message of product efficacy. This perceived product efficacy, in turn, had a positive effect on purchase intention. 
Table 1

The mediation results $(n=150)$

\begin{tabular}{|c|c|c|c|}
\hline Predictors & & $\begin{array}{c}\text { Model } 1 \\
\text { Efficacy } \beta(\mathrm{SE})\end{array}$ & $\begin{array}{c}\text { Model } 2 \\
\text { Intention } B(\mathrm{SE})^{\mathrm{b}}\end{array}$ \\
\hline \multicolumn{4}{|l|}{ Independent variables } \\
\hline Condition d1-speaking ${ }^{\mathrm{a}}$ & & $0.373(0.153)^{*}$ & $0.453(0.165)^{* *}$ \\
\hline Condition d2-demonstration ${ }^{\mathrm{a}}$ & & $1.040(0.153)^{* *}$ & $0.456(0.185)^{* *}$ \\
\hline Efficacy & & & $0.715(0.087)^{* *}$ \\
\hline $\mathrm{R}^{2}$ & & 0.493 & 0.677 \\
\hline $\begin{array}{l}\text { Bootstrap indirect effects on intention } \\
\text { (through efficacy) }{ }^{c}\end{array}$ & $ß(\mathrm{SE})$ & LL $95 \%$ CI & UL $95 \%$ CI \\
\hline \multirow[t]{2}{*}{ Efficacy } & $0.267(0.131)$ & 0.016 & 0.535 \\
\hline & $0.743(0.152)$ & 0.448 & 1.067 \\
\hline
\end{tabular}

Notes: $\mathrm{LL}=$ lower limit; $\mathrm{UL}=$ upper limit; $\mathrm{CI}=$ confidence interval. Unstandardised regression coefficients are reported with standard error in parentheses. ${ }^{a}$ Non-anthropomorphic condition as the reference category. ${ }^{b}$ Direct and total effect. ${ }^{\mathrm{c} B o o t s t r a p}$ sample size $=1000$.

$* p<0.05 ; * * p<0.01$

Results of Study 1 supported our hypothesis that perceived product efficacy would be greater if anthropomorphic character demonstrates the efficacy of the product using human-like behaviour. In the stimulus of Study 1, the product (flu medicine) transformed into human-like figure and demonstrated the efficacy of the product, i.e., fight against the flu symptoms. Results indicate that anthropomorphic demonstration generated the greatest anthropomorphism, compared to speak or non-anthropomorphic conditions. This suggests that the product efficacy that was visualised into human behaviour has generated the greater anthropomorphism, and it was to be the most effective way to deliver the message of product efficacy. In contrast to previous studies, through Study1, we can demonstrate the motion effect of anthropomorphism by using TV ad as experimental stimulus.

As expected, our results found that anthropomorphic character differ in behaviour effect. These findings extended prior research that presenting the product as human (Aggarwal \& McGill, 2007) and human behaviour (Delbaere et al., 2011) would lead to higher evaluations. Arguably, Study 1 provided evidence that participants successfully anthropomorphised the product when the products were presented as human which have human-like features and human-like behaviour.

The anthropomorphic character as a symbol of the product in Study 1 had a medium of human-like appearance, and in Study 2 we will examine the effect of the level of similarity to humans of anthropomorphic character. 


\section{STUDY 2}

Study 2 aims to strengthen the results of Study 1 that demonstrated the efficacy of the product with human behaviour is the most effective. For that purpose, in Study 2 we manipulate human-characters similarity into three levels. The three kinds of characters held demonstrations of product efficacy in the same way as in anthropomorphic demonstration condition in Study 1. Study 2 had two purposes. First, we wanted to test whether the perceived product efficacy varies in the degree of character's similarity to human (H3). We predicted that anthropomorphic character that had a high level of similarity to human would result in a higher perceived product efficacy than anthropomorphic character that had a lower level of similarity to human. Second, we wanted to test the moderating role of anthropomorphic tendencies (H4).

\section{Method}

\section{Design and participants}

Study 2 had three treatment conditions (similarity to human: high vs. moderate vs. low) between participants design. One hundred and fifty undergraduate students (71 male and 79 female) from UAJ, Jakarta participated in this study and were randomly assigned to one of the three conditions.

\section{Stimulus}

Three different versions of an animated TV ad were created for this study and represented each of the three study conditions (high, medium, and low similarity to human) (Appendix 2). Antifluenza was symbolised by the hero character - the shape of the packaging box (low similarity condition), the 2D human-like hero character (moderate similarity condition), and the 3D human-like hero character (high similarity condition). Flu symptoms were portrayed in verbal form and the character of the virus was created in the form of a round green spike (low similarity condition), the 2D horrific green human-like monsters (moderate similarity condition), and the 3D horrific green human-like monsters (high similarity condition). The three animated TV ads had the same storyline, similar to the demonstration condition storyline in Study 1 and had the same narration.

\section{Procedure}

The procedure was similar to Study 1, with two notable differences. First, participants were distributed in groups of 11 to 15 . To avoid the weakness 
of participants' randomness in Study 1, second experiment was conducted in a computer laboratory; each computer played one of the three experimental conditions. Participants watched the ad on each monitor individually. Second, one week after the experiment, we performed the measurement of anthropomorphic tendency. This was to ensure that the measurement was free from the effect of stimulus.

\section{Results}

\section{Manipulation checks}

We averaged seven items to measure anthropomorphism $(\alpha=0.706)$. We conducted ANOVA (similar to human: low, moderate, high) among participant design using anthropomorphism perception as a dependent variable. The ANOVA revealed that participants in high-similarity condition indicated that Antifluenza seemed more similar with the real human than those in low- and moderate-similarity condition $\left[M_{\text {low }}=3.800, S D=0.545 ; M_{\text {moderate }}=4.123, S D=0.564 ; M_{\text {high }}=4.543, S D=0.486\right.$; $F(2,147)=24.447, p=0.000]$. Clarified with contrast tests between moderatesimilarity condition and low-similarity condition $[t=3.030, p($ one-tailed $)=0.002]$ and contrast tests between high-similarity condition and moderate-similarity condition $[t=3.942 ; p$ (one-tailed $)=0.000]$. The control variables: subjective knowledge $[F(2.147)=0.219, p=0.804]$, health motivation $[F(2.147)=1.750$, $p=0.177]$, and attention to ad $[F(2.147)=2.788, p=0.065]$ had no effect. This finding suggested the manipulation processes had been successful.

\section{Perceived product efficacy}

We hypothesized that the participants in the high-similarity condition would perceive product efficacy higher than participants in the low- and moderatesimilarity condition. A one-way ANOVA was conducted with perceived product efficacy $(\alpha=0.639)$ serving as the dependent variable. $\left[M_{\text {low }}=3.933, S D=0.878\right.$; $M_{\text {moderate }}=4.307, S D=0.598 ; \quad M_{\text {high }}=4.607, S D=0.489 ; F(2.147)=12.482$, $p=0.000]$. Dunnett-tests $(>$ control) for high-similarity condition $(p=0.000)$ and moderate-similarity condition $(p=0.006)$; then contrast test between high- and moderate-similarity condition was significant $[t=2.747$; $p$ (one-tailed $)=0.004]$. Thus, H3 was supported, as predicted; perceived product efficacy in the highsimilarity condition was higher than in the low- and moderate-similarity condition. 


\section{Moderation of anthropomorphic tendency}

To test whether anthropomorphic tendency moderate the effect of perceived similarity on perceived product efficacy $(\mathrm{H} 4)$, we conducted a regression analysis with two dummy variables for perceived similarity, anthropomorphic tendency and the interaction of the two. Perceived product efficacy was included in the regression as the dependent variable. Anthropomorphic tendency was measured by 15 items IDAQ (Individual Differences Anthropomorphism Questionnaire) (Cronbach $\alpha=$ 0.775) adopted from Waytz et al. (2010). The results showed that there was a nonsignificant interaction of perceived similarity and anthropomorphic tendency in moderate-similarity condition [vs. low, $b=0.138, S E=0.152,95 \% C I(-0.162$; $0.439), p>0.050$ ] and in high-similarity condition [vs. low, $b=-0.207, S E=0.164$, $95 \% C I(-0.532 ; 0.118), p>0.050]$. Therefore, H4 was not supported. In both the moderate- and high-similarity condition (vs. low), there were no differences in the product efficacy at different levels of anthropomorphic tendencies.

\section{Mediation analysis}

Following Study 1, the current study also tested the mediation role of perceived product efficacy (Table 2). We performed the mediation analysis with purchase intention as dependent variable $(\alpha=0.617)$, perceived similarity as the predictor (two dummy variables), and the perceived product efficacy as the mediating variable, using the PROCESS SPSS macro model 4 (Hayes, 2013; Hayes \& Preacher, 2013). The results of mediation model supported the result of Study 1 to claim the mediation role of perceived product efficacy to the effect of perceived similarity on purchase intention $\left[a_{1} b=0.1232,95 \% C I(0.0369 ; 0.2652)\right.$ and $\left.a_{2} b=0.2221 ; 95 \% C I(0.1119 ; 0.4066)\right]$. The effect of perceived similarity on perceived product efficacy $\left(a_{1}=0.3733, t=2.7648, p<0.010\right.$ and $a_{2}=0.6733$, $t=4.9865, p<0.010)$ and the effect of perceived product efficacy on purchase intention $(b=0.3299, t=3.7586, p<0.010)$ were both significant. The direct effect of anthropomorphic behaviour on purchase intention $\left(c_{1}=-0.0432, t=-0.2929\right.$ $p>0.050$ and $c_{2}=0.2479, t=1.5951 p>0.050$ ) was not significant (Table 2) indicating that full mediation occurred (Zhao, Lynch, \& Chen, 2010; Baron \& Kenny, 1986).

\section{Test for alternative models}

Previous research of advertising shows that the effect of ad exposure on purchase intention is mediated by attitude toward the ad $\left(\mathrm{A}_{\mathrm{ad}}\right)$ and mood (MacKenzie \& Lutz, 1989). To get a better understanding of the overall indirect effect of perceived product efficacy, we tested indirect effect by including perceived product efficacy, 
Table 2

The mediation results $(n=150)$

\begin{tabular}{|c|c|c|c|}
\hline Predictors & & $\begin{array}{c}\text { Model } 1 \\
\text { Efficacy } ß(\mathrm{SE})\end{array}$ & $\begin{array}{c}\text { Model } 2 \\
\text { Intention } \beta(\mathrm{SE})^{\mathrm{b}}\end{array}$ \\
\hline \multicolumn{4}{|l|}{ Independent variables } \\
\hline Condition d1-moderate similarity ${ }^{a}$ & & $0.373(0.135)^{* *}$ & $-0.043(0.147)$ \\
\hline Condition d2-high similarity ${ }^{a}$ & & $0.673(0.135)^{* *}$ & $0.248(0.155)$ \\
\hline Efficacy & & & $0.330(0.088)^{* *}$ \\
\hline $\mathrm{R}^{2}$ & & 0.381 & 0.391 \\
\hline $\begin{array}{l}\text { Bootstrap indirect effects on intention } \\
\text { (through efficacy) }^{c}\end{array}$ & $ß(\mathrm{SE})$ & LL $95 \%$ CI & UL 95\% CI \\
\hline \multirow[t]{2}{*}{ Efficacy } & $0.123(0.053)$ & 0.037 & 0.265 \\
\hline & $0.222(0.070)$ & 0.112 & 0.407 \\
\hline
\end{tabular}

Notes: Unstandardised regression coefficients are reported with standard error in parentheses. ${ }^{\text {aLow-similarity }}$

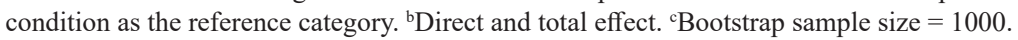

$* p<0.05 ; * * p<0.01$

$\mathrm{A}_{\text {ad }}$ and mood in a model. Perceived product efficacy became a significant mediator $\left[a_{1} b=0.1079 ; 95 \% C I(0.0339 ; 0.2175)\right.$ and $a_{2} b=0.1947 ; 95 \% C I(0.0920$; $0.3467)]$, but the other two did not. $\mathrm{A}_{\text {ad }}$ indirect effect was not significant $a_{1} b=$ $0.0098 ; 95 \% C I(-0.0561 ; 0.1186)$ and $a_{2} b=0.1415 ; 95 \% C I(0.0391 ; 0.3231)$ and so did the indirect effect of $\operatorname{mood}\left(a_{1} b=-0.0075 ; 95 \% C I(-0.0846 ; 0.0259)\right.$ and $a_{2} b=-0.0204 ; 95 \% C I(-0.1384 ; 0.0935)$. Hence, it can be argued that the perceived product efficacy was claimed to be the most powerful mediator in the anthropomorphic demonstration effect on purchase intention.

\section{Discussion}

The results showed that a character that has high physical similarity to a real human was able to produce the greatest positive perceived product efficacy compared to the less human-like character (in the shape of the packaging box) and a character with a moderate level of similarity to a human. The results also suggested that the anthropomorphic tendency of participants did not contribute to the result.

The physical characteristics were very similar to humans in products; they encouraged consumers to perceive human character in the products. The presence of a physical appearance similar to a human was required, so that the audience could feel the intention, courage, ability, and ambition of the product to overcome the problem. The product was presented as a hero, to whom it has intention, power and ability to relieve the flu symptoms, while at the same time also being brave and 
ambitious to defeat the enemies, namely the flu symptoms. According to Epley et al. (2007), the more similar in appearance, the more people anthropomorphise an object. This study supports previous research that the presence of human physical appearance and motion made the mental state of the object (intention, emotion, consciousness) could be perceived (Morewedge et al., 2007). Study 2 result implies that product efficacy demonstration in advertising required a character that was more physically similar to humans, so that the participants put some belief in the efficacy of the product.

\section{CONCLUSION}

\section{Summary of Findings and Contribution to Theory and Advertisers}

We proposed anthropomorphic demonstration as a creative ad tactic that demonstrates product efficacy using human-like behaviour. The key contribution of this research is to bring anthropomorphism on delivering an advertising message which is difficult to comprehend such as product efficacy messages that cannot be seen, touched, or felt; perceived abstract. The anthropomorphic demonstration can create ease, and in turn the ease encouraged positive perceptions to product efficacy. Anthropomorphic behaviour that has been tested empirically in our research enriches the creativity of advertising, particularly on a demonstration tactics that are commonly used.

In advertising research methodology especially research on anthropomorphism in advertising area, we believe that the use of TV media as a stimulus, as in our study, is important in order to perceive the motion effect of human behaviour. Motion makes human traits seem real. This motion makes any manipulation of the ad character able to trigger audiences' anthropomorphism; even the packaging box-shaped character in Study 2 could create anthropomorphism although at a low level. This research shows that consumers' anthropomorphism can be triggered by marketers by manipulating marketing stimuli like advertising. Human characteristics - appearance, behaviour, character - can be manipulated in such a way to produce a positive effect of anthropomorphism.

Nevertheless, the anthropomorphic tendency as an individual difference variable in this research is not supported by the data. This study was conducted in Indonesia, which has a collectivistic culture. Communities in collectivistic culture are interdependent and build relationships in a large family. Sociality motivation is one of the factors that affect the level of a person's tendency to anthropomorphism (Epley et al., 2007), lack of social relationships with others will encourage a 
tendency to anthropomorphise non-human objects. The Indonesian participants in our research were predicted to have relatively fulfilled sociality motivation needs; so Study 2 showed participants' anthropomorphic tendencies were at a low level.

Lastly, the results also supported our expectation that liking this kind of advertising does not automatically lead to purchase intention. On the additional testing that we did, perceived product efficacy was proven to have stronger mediation effects on purchase intention than attitude toward the $\mathrm{ad}\left(\mathrm{A}_{\mathrm{ad}}\right)$. In other words, purchase intention was formed due to a positive perceived product efficacy, not solely because of a like for advertising.

\section{Limitations and Future Research}

We incorporated the theory of anthropomorphism that included the attribution of human mental states to non-human objects (Epley et al., 2007; Waytz et al., 2010) into demonstration tactics in advertising. In doing so, we used a hero archetype as the brand personality (Mark \& Pearson, 2001) and examined the effects of similarity to humans. Human nature that is brave, tough, and has a strong intention (hero archetype) can be perceived on highly human-like appearance. One limitation of this research is no specific criteria were used to determine the level of similarity. Future research should use specific criteria of similarity to human for example by considering the effect of the uncanny valley (Mori, 1970) in order to obtain a more optimum level of similarity.

To achieve the research purpose, our study was limited to products that had abstract efficacy, the medicine product. Future research should also extend our framework to other domains in order to answer questions about the type of products which anthropomorphic demonstration tactic can be more effectively used. For example, by considering the product involvement (Rossiter, Percy, \& Donovan, 1991), what the effect of anthropomorphic demonstration ad would be if consumers had a high involvement with the product, whether this kind of ad would be sufficient to provide the required information or reduce the perceived product risk.

Our study was limited to the hero archetypal, as the result of our pilot study, the other archetypes such as caregiver or magicians (Mark \& Pearson, 2001) we believe are suitable to demonstrate the product efficacy. Nowadays a lot of consumers prefer products which have instant benefits. Human behaviour as a magician might be suitable to explain the efficacy of these products. Moreover, future research might be interested in advertising messages about health care product, which were demonstrated by a caregiver. 
Considering the model of advertising effectiveness by Lutz et al. (1983) in each of our studies, we conducted additional testing that entered $\mathrm{A}_{\mathrm{ad}}$ variable into the mediation model, and proved that $\mathrm{A}_{\mathrm{ad}}$ also mediates the effect of anthropomorphic demonstration ad on purchase intention, although the mediation effect of perceived product efficacy was stronger than $\mathrm{A}_{\text {ad. }}$. Future research needs to examine whether $\mathrm{A}_{\text {ad }}$ is the antecedent of the perceived product efficacy. Furthermore, we also need to measure the level of familiarity and the level of ease in order to strengthen the results of this study that the sense of familiarity with human behaviour of this kind of ad makes advertising messages easier to capture. 


\section{APPENDIX 1}

Sample of storyboard TV ad (Study 1)

Demonstration condition: Study 1
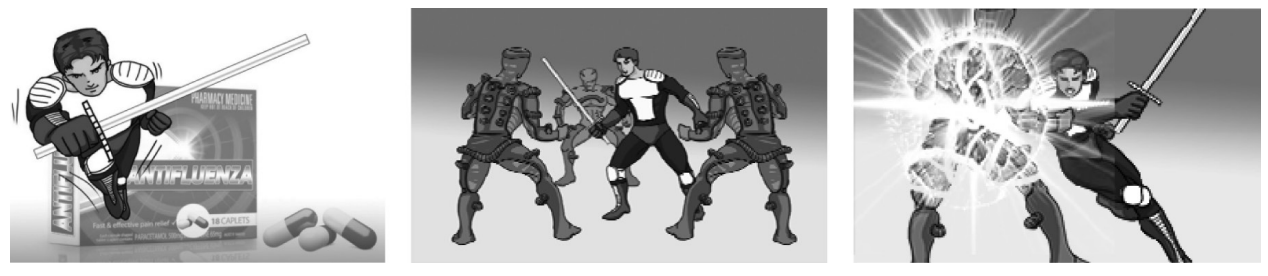

Speaking condition: Study 1
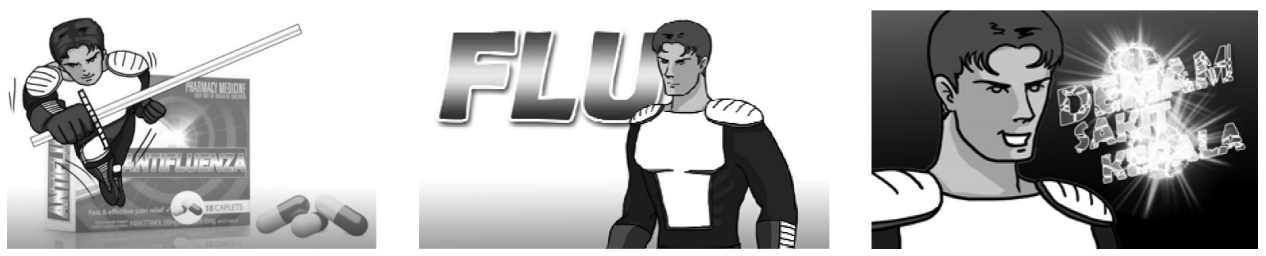

\section{APPENDIX 2}

Sample of anthropomorphic character: Physical similarity to humans (Study 2)

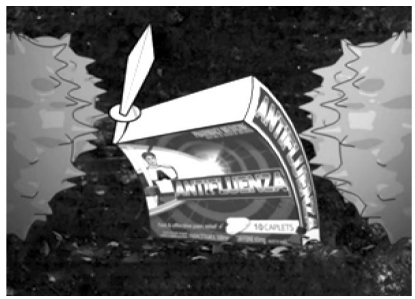

Low

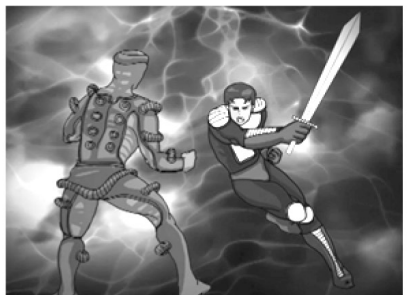

Moderate

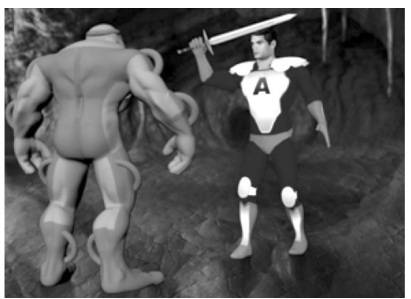

High 


\section{REFERENCES}

Aaker, J.L. (1997). Dimensions of brand personality. Journal of Marketing Research, 34, 347-356. https://doi.org/10.2307/3151897

Aggarwal, P., \& McGill, A.L. (2007). Is that car smiling at me? Schema congruity as a basis for evaluating anthropomorphized products. Journal of Consumer Research, 34, 468-479. https://doi.org/10.1086/518544

Aggarwal, P., \& McGill, A.L. (2012). When brands seem human, do humans act like brands? Automatic behavioral priming effects of brand anthropomorphism. Journal of Consumer Research, 39(2), 307-323. https://doi.org/10.1086/662614

Arias-Bolzmann, L., Chakraborty, G., \& Mowen, J.C. (2000). Effects of absurdity in advertising: The moderating role of product category attitude and the mediating role of cognitive responses. Journal of Advertising, 29, 35-49. https://doi.org/10. 1080/00913367.2000.10673602

Baron, R.M., \& Kenny, D.A. (1986). The moderator-mediator variable distinction in social psychological research: Conceptual, strategic, and statistical considerations. Journal of Personality and Social Psychology, 51, 1173-1182. https://doi. org/10.1037/0022-3514.51.6.1173

Belch, G.E., \& Belch, M.A. (2012). Advertising and promotion. An integrated marketing communications perspective (9th ed.). New York: McGraw Hill.

Callcott, M.F., \& Lee, W. (1994). A content analysis of animation and animated spokescharacters in television commercials. Journal of Advertising, 23(4), 1-12. https://doi.org/10.1080/00913367.1943.10673455

Callcott, M.F., \& Lee, W. (1995). Establishing the spokescharacter in academic inquiry: Historical overview and framework for definition. Advances in Consumer Research, 22, 144-151.

Campbell, J. (2004). The hero with a thousand faces. New Jersey: Princeton University Press.

Chandler, J.J., \& Schwarz, N. (2010). Use does not wear ragged the fabric of friendship: Thinking of objects as alive makes people less willing to replace them. Journal of Consumer Psychology, 20, 138-145. https://doi.org/10.1016/j.jcps.2009.12.008

Connell, P.M. (2013). The role of baseline physical similarity to humans in consumer responses to anthropomorphic animal images. Psychology and Marketing, 30(6), 461-468. https://doi.org/10.1002/mar.20619

Cox, A.D., Cox, D., \& Mantel S.P. (2010). Consumer response to drug risk information: The role of positive affect. Journal of Marketing, 31, 31-44. https://doi.org/10.1509/ jmkg.74.4.31

Delbaere, M., McQuarrie, E., \& Philips, B. (2011). Personification in advertising, using a visual metaphor to trigger anthropomorphism. Journal of Advertising, 40(1), 121-130. https://doi.org/10.2753/JOA0091-3367400108

Deighton, J., Romer, D., \& McQueen, J. (1989). Using drama to persuade. Journal of Consumer Research, 16, 335-343. https://doi.org/10.1086/209219

Epley, N., Waytz, A., \& Cacioppo, J.T. (2007). On seeing human: A three-factor theory of anthropomorphism. Psychological Review, 114(4), 864-886. https://doi.org/ 10.1037/0033-295X.114.4.864 
Epley, N., Waytz, A., Akalis, S., \& Cacioppo, J.T. (2008). When we need a human: Motivational determinants of anthropomorphism. Social Cognition, 26(2), 143155. https://doi.org/10.1521/soco.2008.26.2.143

Fishbein, M., \& Ajzen, I. (1975). Belief, attitude, intention, and behavior: An introduction to theory and research. Reading, Mass: Addison-Wesley.

Folse, J.A.G., Netemeyer, R.G., \& Burton, S. (2012). Spokescharacters: How the personality traits of sincerity, excitement, and competence help to build equity. Journal of Advertising, 41(1), 17-32. https://doi.org/10.2753/JOA0091-3367410102

Garretson, J.A., \& Niedrich, R.W. (2004). Spokes-characters creating character trust and positive brand attitudes. Journal of Advertising, 33(2), 25-36. https://doi. org/10.1509/jmkg.2005.69.4.118

Garretson, J.A., \& Burton, S. (2005). The role of spokescharacters as advertisement and package cues in integrated marketing communications. Journal of Marketing, 69, $118-132$.

Guthrie, S.E. (1995). Faces in the clouds: A new theory of religion. New York: Oxford University Press.

Hayes, A.F. (2013). Introduction to mediation, moderation, and conditional process analysis: A regression-based approach. New York: The Guilford Press.

Hayes, A.F., \& Preacher, K.J. (2013). Statistical mediation analysis with a multicategorical independent variable. British Journal of Mathematical and Statistical Psychology, 67(3), 451-470.

Heider, F. \& Simmel, M. (1944). An experimental study of apparent behavior. The American Journal of Psychology, 57(2), 243-259. https://doi.org/10.2307/1416950

Kim, S., \& Labroo, A.A. (2011). From inherent value to incentive value: When and why pointless effort enhances consumer preference. Journal of Consumer Research, 38, 712-742. https://doi.org/10.1086/660806

Kim, S., \& McGill, A.L. (2011). Gaming with Mr. Slot or gaming the slot machine? Power, anthropomorphism, and risk perception. Journal of Consumer Research, 38, 1-14. https://doi.org/10.1086/658148

Labroo, A.A., Dhar, R., \& Schwarz, N. (2008). Of frog wines and frowning watches: Semantic priming, perceptual fluency, and brand evaluation. Journal of Consumer Research, 34, 819-831. https://doi.org/10.1086/523290

Landwehr, J.R., McGill, A.L., \& Herrmann, A. (2011). It's got the look: The effect of friendly and aggressive "facial" expressions on product liking and sales. Journal of Marketing, 75, 132-146. https://doi.org/10.1509/jmkg.75.3.132

Lin, K-W, \& Wang, Y-J. (2012). The influence of animated spokescharacters in customer orientation. The International Journal of Organizational Innovation, 4(4), 142154.

Lutz, R.J., MacKenzie, S.B., \& Belch, G.E. (1983). Attitude toward the ad as a mediator of advertising effectiveness: Determinants and consequences. Advances in Consumer Research, 10, 532-539.

MacInnis, D.J., \& Price, L.L. (1987). The role of imagery in information processing: Review and extensions. Journal of Consumer Research, 13, 473-491. https://doi. org/10.1086/209082 
MacKenzie, S.B., \& Lutz, R.J. (1989). An empirical examination of the structural antecedents of attitude toward the ad in an advertising pretesting context. Journal of Marketing, 53, 48-65. https://doi.org/10.2307/1251413

Mark, M., \& Pearson, C.S. (2001). The hero and the outlaw: Building extraordinary brands through the power of archetypes. New York: McGraw Hill.

May, F., \& Monga, A. (2014). When time has a will of its own, the powerless don't have the will to wait: Anthropomorphism of time can decrease patience. Journal of Consumer Research, 40, 924-942. https://doi.org/10.1086/673384

McQuarrie, E.F., \& Phillips, B.J. (2005). Indirect persuasion in advertising: How consumers process metaphors presented in pictures and words. Journal of Advertising, 34(2), 7-20. https://doi.org/10.1080/00913367.2005.10639188

Miesler, L. (2011). Imitating human forms in product design: How does anthropomorphism work, when does it work, and what does it affect? $\mathrm{PhD}$ dissertation, University of St. Gallen, Switzerland.

Morewedge, C.K., Preston, J., \& Wegner, D.M. (2007). Timescale bias in the attribution of mind. Journal of Personality and Social Psychology, 93(1), 1-11. https://doi. org/10.1037/0022-3514.93.1.1

Mori, M. (1970). The uncanny valley (translated by Karl F. MacDorman and Takashi Minato). Energy, 7(4), 33-35.

Neeley, S. M., \& Schumann, D.W. (2004). Using animated spokes-characters in advertising to young children. Does increasing attention to advertising necessarily lead to product preference? Journal of Advertising, 33(3), 7-23. https://doi.org/10.1080/ 00913367.2004.10639166

Pearson, C. (1989). The hero within: Six archetypes we live by (expanded ed.). San Francisco: Harper \& Row Publishers.

Peracchio, L.A., \& Meyers-Levy, J. (1994). How ambiguous cropped objects in ad photos can affect product evaluations. Journal of Consumer Research, 21, 190-204. https://doi.org/10.1086/209392

Pierce, K. (2002). What if the energizer bunny were female? Importance of gender in perceptions of advertising spokescharacter effectiveness. Sex Roles, 45(11/12), 845-858. https://doi.org/10.1023/A:1015696504841

Putrevu, S., \& Lord, K.R. (1994). Comparative and noncomparative advertising: Attitudinal effects under cognitive and affective involvement conditions. Journal of Advertising, 23(2), 77-90. https://doi.org/10.1080/00913367.1994.10673443

Rossiter, J.R., Percy, L., \& Donovan, R.J. (1991) A better advertising planning grid. Journal of Advertising Research, 31(5), 11-21.

Shiv, B., Carmon, Z., \& Ariely, D. (2005). Placebo effects of marketing actions: Consumers may get what they pay for. Journal of Marketing Research, 42, 383-393. https://doi.org/10.1509/jmkr.2005.42.4.383

Smith, H.S. (2008). Emotional evaluation of product/system. PhD dissertation, University of Central Florida.

Stafford, M.R., Stafford, T., \& Day, E. (2002). A contingency approach: The effects of spokesperson type and service type on service advertising perceptions. Journal of Advertising, 31(2), 17-34. https://doi.org/10.1080/00913367.2002.10673664 
Waytz, A., Cacioppo, J., \& Epley, N. (2010). Who sees human?: The stability and importance of individual differences in anthropomorphism. Perspectives on Psychological Science, 5(3), 219-232. https://doi.org/10.1177/1745691610369336

Zhao, X., Lynch Jr. J.G., \& Chen, Q. (2010). Reconsidering Baron and Kenny: Myths and truths about mediation analysis. Journal of Consumer Research, 37,197-206. https://doi.org/10.1086/651257

Zhu, M., Billeter, D.M., \& Inman, J.J. (2012). The double-edged sword of signaling effectiveness: When salient cues curb post-purchase consumption. Journal of Marketing Research, 49(1), 26-38. https://doi.org/10.1509/jmr.09.0531 